\title{
PENGARUH CATALYTIC CONVERTER BERBAHAN TEMBAGA 0,6 MM BERBENTUK SIRIP TERHADAP HASIL EMISI GAS BUANG PADA HONDA BEAT TAHUN 2015
}

\author{
Budiyono \\ Program Studi Teknik Mesin Diploma Tiga \\ Universitas Muhammadiyah Pekajangan Pekalongan Jawa Tengah \\ Email : Budiyonosp75@gmail.com
}

\begin{abstract}
Abstrak
Catalytic Converter adalah salah satu alat yang digunakan mengurangi emisi gas buang yang berbahaya bagi manusai. Dimana alat tersebut terbuat dari bahan Tembaga dengan tebal 0,6 mm bahan jenis ini mampu mengurangi emisi gas buang ( $\mathrm{HC}, \mathrm{CO})$ cukup tinggi antara $80 \%$ sampai $16 \%$. Pada penelitian ini penulis mencoba mengkaji bagaimana pengaruh penggunaan catalytic converter berbahan tembaga untuk mengurangi nilai kadar gas CO dan HC pada Honda Beat Tahun 2015. Pengujian ini dilakukan dengan dua tahap yaitu pengujian dengan knalpot standar dan knalpot bercatalytic converter dengan variasi putaran mesin $1500 \mathrm{rpm}, 2000 \mathrm{rpm}, 2500 \mathrm{rpm}$, $3000 \mathrm{rpm}, 3500 \mathrm{rpm}, 4000 \mathrm{rpm}$.Hasil dari penelitian ini adalah Pengaruh penggunaan catalytic converter dengan bahan tembaga dengan model sirip mengalami penurunan kadar emisi gas CO paling efektif pada putaran mesin $1500 \mathrm{rpm}$ sebesar 2,357\% dari 4,89\% menjadi 2,54\% dan nilai kadar emisi gas HC turun pada rpm 1500 sebesar 2726 ppm dari 9.999 ppm menjadi 7273 ppm.
\end{abstract}

Kata Kunci: Emisi gas buang ; Catalytic converter; katalis tembaga ; CO ; HC

\begin{abstract}
Catalytic Converter is one of the tools used to reduce exhaust emissions that are harmful to humans. Where the tool is made of copper with a thickness of $0.6 \mathrm{~mm}$ this type of material is able to reduce exhaust emissions $(\mathrm{HC}, \mathrm{CO})$ is quite high between $80 \%$ to 16\%. In this study the authors tried to examine how the influence of using copper catalytic converters to reduce the value of $\mathrm{CO}$ and HC gas levels in the 2015 Honda Beat. This test was carried out in two stages, namely testing with standard exhaust and catalytic converter exhausts with variations of engine speed $1500 \mathrm{rpm}, 2000 \mathrm{rpm}, 2500$ rpm, $3000 \mathrm{rpm}, 3500 \mathrm{rpm}, 4000 \mathrm{rpm}$. The results of this study are the effect of the use of catalytic converters with copper material with the fin model has decreased the most effective levels of $C O$ gas emissions at 1500 rpm engine speed of $2.357 \%$ from $4.89 \%$ to $2.54 \%$ and the value of HC gas emission levels decreased at $1500 \mathrm{rpm}$ by $2726 \mathrm{ppm}$ from 9,999 ppm to 7273 ppm.
\end{abstract}

Keywords: Exhaust gas emissions ; Catalytic converter; copper catalyst;CO; HC

\section{PENDAHULUAN}

Pencemaran lingkungan sebagai salah satu penyebabkan pemanasan global telah menjadi isu penting diseluruh dunia, tidak terkecuali Indonesia. Meningkatnya jumlah penduduk, aktivitas ekonomi dan transportasi semakin hari semakin meningkat pencemaran lingkungan [1] . 
Diindonesia kurang lebih $70 \%$ pencemaran udara disebabkan oleh emisi gas buang kendaraan bermotor. Emisi gas buang dari kendaraan bermotor dapat menimbulkan negatif bagi kesehatan manusia maupun lingkungan .Pertumbuhan jumlah kendaraan sepeda motor dari tahun ketahun semakin bertambah sehingga polusi akibat gas buang kendaraan akan semakin berbahaya bagi manusia. Pertumbuhan jumlah kendaraan bermotor yang semakin meningkat dari tahun ke tahun sehingga polusi akibat gas buang kendaraan juga akan meningkat [2] .

Peraturan menteri Negara lingkungan hidup Nomor 05 tahun 2006 Tentang batas yang diijinkan emisi gas buang sepeda motor [3] .Salah satu alat untuk untuk mengurangi emisi gas buang ( $\mathrm{CO}$ dan HC) adalah dengan pemasangan Catalytic Converter , bahan yang digunakan adalah material tembaga.Tembaga adalah logam merah muda yang lunak, dapat ditempa, dan liat. Melebur pada $1038^{\circ}$ C. Karena potensial standarnya positif, $(+0,34 \mathrm{~V}$ untuk pasangan $\mathrm{Cu}$ ), logam tak larut dalam asam klorida dan asam sulfat encer, meskipun dengan adanya oksigen tembaga bisa larut sedikit. Tembaga memiliki sifatsifat antara lain : berat jenisnya 8,9 titik lelehnya sampai $1083^{\circ} \mathrm{C}$, mempunyai daya hantar listrik dan panas yang baik, dan tahan pengaruh udara lembab karena melindungi diri dengan karbonat tembaga [4].

Disamping itu untuk membuat catalityc Converter harga yang lebih murah, mudah dikerjakan dan mudah didapat untuk dijadikan catalityc Converter yang mampu mengurangi emisi gas buang (HC,CO) cukup tinggi antara $16 \%$ sampai $80 \%$ (Dwyer, 1973).

\section{Catalytic Converter}

Catalytic converter adalah suatu alat yang dipasang di kendaraan yang mempunyai fungsi untuk mengurangi emisi gas buang pada kendaraan tersebut.
Semakin merata gas buang mengenai permukaan catalytic converter maka akan semakin besar terjadinya proses reduksi emisi [5] .

Catalytic convertersudah digunakan di Amerika serikat sejak tahun 1975 karena peraturan Envoronmental Pretection Agency (EPA) yang semakin ketat tentang gas buang kendaraan bermotor roda dua, alat ini mengkonversi senyawa-senyawa toksit dalam gas buang menjadi zat-zat yang kurang toksit atau tidak toksit [6].

Harga catalytic converter yang terbuat dari palladium dan rodium harga di pasaran mahal. Selain itu katalitik tersebut juga sangat rentan terhadap bahan bakar premium yang memiliki kadar timbal $(\mathrm{Pb})$ yang bisa merusak fungsi katalitik [7] .Tembaga memiliki sifat-sifat antara lain: berat jenisnya 8,9 , titik lelehya sampai $1083^{\circ} \mathrm{C}$, mempunyai daya hantar listrik dan panas yang baik, dan tahan pengaruh udara lembab karena melindungi diri dengan karbonat tembaga [8] .

Penelitian tentang pembuatan Catalytic Converter Berbahan Tembaga sudah banyak dibuat antara lain

1. Pengaruh Penggunaan Metallic Catalytic Converter Berbahan Tembaga Dan Aplikasi Teknologi Sass Terhadap Performa Sepeda Motor Honda New Mega Pro oleh Rido Manunggal ( Universitas Negeri Surabaya )

2. Rancang Bangun Catalytic Converter Material Substrat Tembaga Berlapis Mangan Untuk Mereduksi Emisi Gas Karbon Monoksida Motor Bensin Oleh RM. Bagus Irawan (Universitas Muhammadiyah Semarang)

3. Pengaruh Catalytic Converter Dengan Model Jaring Terhadap Emisi Gas Buang Pada Kendaraan Bermotor Oleh Siswo Aswito (Universitas Islam Malang)

Maka penelitian ingin membuat Catalytic Converter Berbahan Tembaga 0,6 Mm Pada Honda Beat Tahun 2015 yang 
banyak digunakan pada masa sekarang dan menyumbang gas emisi paling besar.

\section{Emisi Gas Buang}

Emisi gas buang merupakan sisa hasil pembakaran mesin bermotor. Biasanya emisi gas buang ini terjadi karena pembakaran yang tidak sempurna dari sistem pembuangan dan pembakaran mesin serta lepasnya partikel-partikel karena kurang tercukupinya oksigen dalam proses pembakaran tersebut [3] .

Pencemaran udara saat ini sudah sangat mengkhawatirkan, . Ada lima unsur dalam gas buang kendaraan yang diukur yaitu senyawa HC (Hidrokarbon), CO (Karbon Monooksida), CO2 (Karbon Dioksida), O2 (Oksigen) dan senyawa NOx ( Nitrogen Oksida ). Sedangkan negara - negara yang tidak terlalu ketat emisinya hanya mengukur empat senyawa unsur gas buang yaitu Senyawa HC, CO, $\mathrm{CO} 2$, dan $\mathrm{O} 2$. bensin adalah senyawa hidrokarbon, jadi setiap HC yang didapat di gas buang kendaraan menunjukkan adanya bensin yang tidak terbakar dan terbuang bersama sisa pembakaran. Apabila suatu senyawa hidrokarbon terbakar sempurna (bereaksi dengan oksigen), maka hasil reaksi pembakaran tersebut adalah karbondioksida $(\mathrm{CO} 2)$ dan air (H2O) [9]

\section{Karbon Monoksida (CO)}

Carbon Monoxide (CO) adalah gas yang sangat beracun yang terbentuk karena terjadinya pembakaran yang tidak sempurna, misalnya campuran bahan bakar dan udara terlalu kaya, sehingga kekurangan udara $(\mathrm{O} 2)$ untuk mengikat Carbon, akibatnya $\mathrm{CO}$ menjadi tinggi. Besar kecilnya $\mathrm{CO}$ diukur dalam satuan prosen (\%) [10].

\section{Hidrokarbon (HC)}

Petrol atau gasolin adalah merupakan campuran dari isomer-isomer heptana dan oktana. Fraksi bensin merupakan produk Hydrocarbon (HC) merupakan unsur kimia dari bahan bakar baik bensin, LPG ( liquified pretrolium gas ) dan bahan bakar solar.Dalam proses pembakarannya bensin akan menghasilkan unsur $\mathrm{HC}$ yang merupakan gas beracun yang selalu timbul dalam proses pembakaran, $\mathrm{HC}$ diukur dengan satuan ppm (Part Per Million) [10].Pembakaran tidak sempurna disebabkan adanya kandungan oksigen yang terlalu banyak dan atau terlalu sedikit oksigen, dengan istilah campuran kurus dan campuran gemuk [11].

\section{METODOLOGI PENELITAN \\ Variabel Penelitian}

1. Variabel terikat adalah Variabel pada penelitian ini adalah emisi gas buang $\mathrm{HC}$ dan $\mathrm{CO}$.

2. Variabel Bebas adalah Variabel pada penelitian ini yaitu :

a. Pengujian pada idle $1500 \mathrm{rpm}$, $2000 \mathrm{rpm}, 2500 \mathrm{rpm}, 3000 \mathrm{rpm}$, $3500 \mathrm{rpm}, 4000 \mathrm{rpm}$.

Desain catalytic converter dengan model sirip tak beraturan

Desain Catalytic Converter

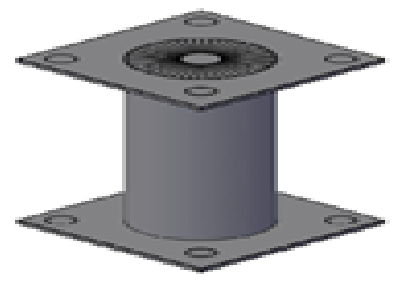

Gambar 1. Catalytic Converter

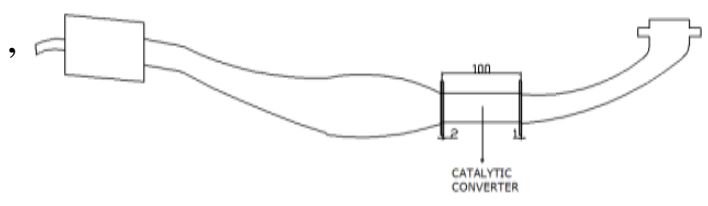

Gambar 2. Desain Knalpot Terpasang Catalytic Converter

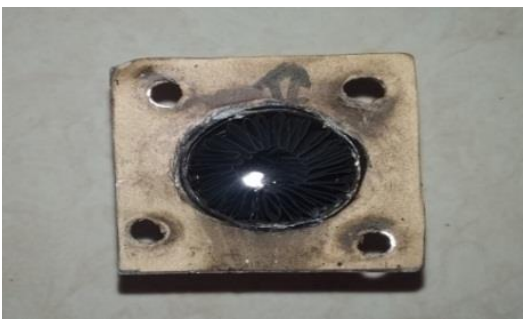

Gambar 3.Catalytic Converter

\section{Analisa Data}

Penelitian ini menggunakan metode analisis data deskriptif, dimana data yang diperoleh dari hasil pengujian mesin 
dimasukkan ke dalam tabel, dan ditampilkan dalam bentuk grafik kemudian dibandingkan dan dianalisis kadar emisi gas buang kendaraan bermotor berupa gas $\mathrm{CO}$ dan $\mathrm{HC}$ mesin sepeda motor Honda Beat tahun 2015 dengan penggunaan Catalityc Converter Tembaga $(\mathrm{Cu})$ dan tanpa menggunakan Catalityc Converter.

\section{HASIL DAN PEMBAHASAN}

Hasil Uji

Tabel 1. Hasil Uji Dengan Knalpot

Standar

\begin{tabular}{|c|c|c|}
\hline $\begin{array}{c}\text { Putaran } \\
\text { Mesin }\end{array}$ & CO $(\%)$ & HC (ppm) \\
\hline $1500 \mathrm{rpm}$ & $4,89 \%$ & $9999 \mathrm{ppm}$ \\
\hline $2000 \mathrm{rpm}$ & $4,88 \%$ & $9999 \mathrm{ppm}$ \\
\hline $2500 \mathrm{rpm}$ & $5,88 \%$ & $9999 \mathrm{ppm}$ \\
\hline $3000 \mathrm{rpm}$ & $5,67 \%$ & $9999 \mathrm{ppm}$ \\
\hline $3500 \mathrm{rpm}$ & $5,93 \%$ & $9999 \mathrm{ppm}$ \\
\hline $4000 \mathrm{rpm}$ & $6,05 \%$ & $9999 \mathrm{ppm}$ \\
\hline
\end{tabular}

Tabel 2. Hasil Uji Dengan Knalpot Bercatalytic Converter

\begin{tabular}{|c|c|c|}
\hline $\begin{array}{c}\text { Putaran } \\
\text { Mesin }\end{array}$ & CO (\%) & HC (ppm) \\
\hline $1500 \mathrm{rpm}$ & $2,54 \%$ & $7273 \mathrm{ppm}$ \\
\hline $2000 \mathrm{rpm}$ & $3,87 \%$ & $7630 \mathrm{ppm}$ \\
\hline $2500 \mathrm{rpm}$ & $4,60 \%$ & $8523 \mathrm{ppm}$ \\
\hline $3000 \mathrm{rpm}$ & $3,99 \%$ & $8784 \mathrm{ppm}$ \\
\hline $3500 \mathrm{rpm}$ & $4,06 \%$ & $9524 \mathrm{ppm}$ \\
\hline $4000 \mathrm{rpm}$ & $4,56 \%$ & $9999 \mathrm{ppm}$ \\
\hline
\end{tabular}

Pembahasan

Perbandingan Nilai CO Dengan Knalpot Standar Dan Knalpot Bercatalytic Converter

Dari perbandingan data diatas kinerja knalpot dengan catalytic converter pada saluran gas buang akan menurunkan konsentrasi polutan CO.Dimulai dari putaran yang paling rendah yaitu 1500 rpm keputaran yang lebih tinggi hingga 4000 rpm, dari data emisi diperoleh penurunan nilai konsentrasi emisi gas $\mathrm{CO}$ yang cukup signifikan terjadi pada awal putaran $1500 \mathrm{rpm}$ hingga $4000 \mathrm{rpm}$ yaitu nilai konsentrasinya turun sebesar $1,62 \%$ dari $5,55 \%$ menjadi $3,93 \%$.

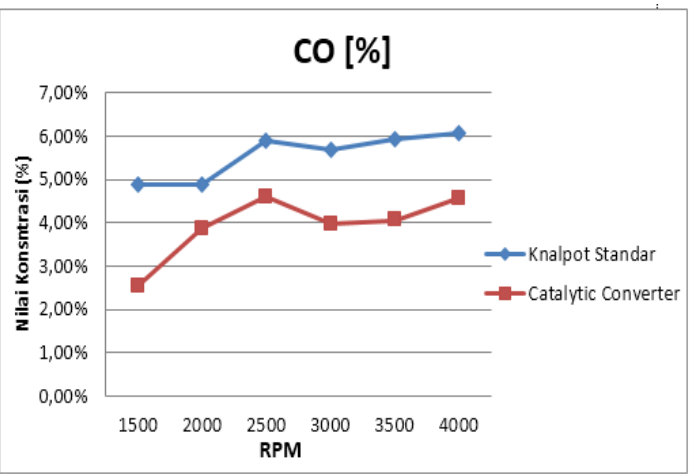

Gambar 4. Grafik Perbandingan Nilai CO Dengan Knalpot Starndar Dan Knalpot Bercatalytic Converter Perbandingan Nilai HC Dengan Knalpot Starndar Dan Knalpot Bercatalytic Converter

Pada grafik dibawah ini bisa dilihat bahwa titik warna biru menunjukan konsentrasi emisi terhadap putaran mesin pada knalpot standar dan titik warna merah menunjukan konsentrasi emisi terhadap putaran mesin pada knalpot catalytic converter.Dari perbandingan data diatas kinerja knalpot catalytic converterpada saluran gas buang akan menurunkan konsentrasi polutan HC.Dimulai dari putaran yang paling rendah yaitu $1500 \mathrm{rpm}$ keputaran yang lebih tinggi hingga $4000 \mathrm{rpm}$, dari data emisi diperoleh penurunan nilai konsentrasiemisi gas $\mathrm{HC}$ yang cukup signifikan terjadi pada awal putaran 1500 rpm hingga 3500 rpm yaitu nilai konsentrasinya turun sebesar 1653 ppm dari 9999 ppm menjadi 8346 ppm.

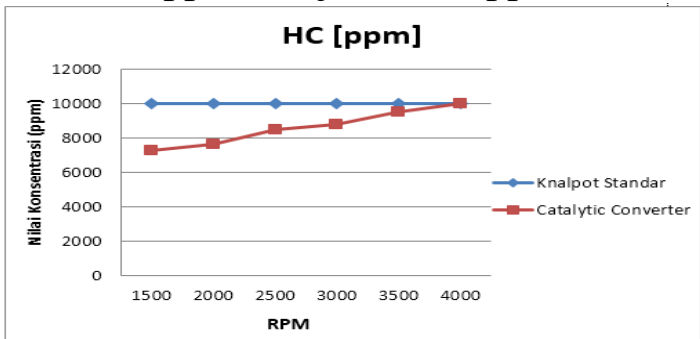

Gambar 5. GrafikPerbandingan Emisi Gas HC Dengan Knalpot Starndar Dan Knalpot Bercatalytic Converter 


\section{KESIMPULAN}

Dari hasil Penelitian ini yang telah dilakukan, didapatkan kesimpulan sebagai berikut :

1. Pada saat pengujian dengan knalpot standar kadar emisi gas CO paling rendah terjadi pada $2000 \mathrm{rpm}$ dengan kadar emisi gas CO sebesar 4,88\% namun kadar gas $\mathrm{HC}$ tidak mengalami penurunan pada putaran mesin 1500 rpm hingga putaran mesin $4000 \mathrm{rpm}$ yaitu 9999 ppm dan kadar emisi paling tinggi gas $\mathrm{CO}$ terjadi pada putaran mesin $4000 \mathrm{rpm}$ dengan kadar gas CO sebesar 6,05\%. Sedangkan pada knalpot dengan catalytic converter kadar emisi gas $\mathrm{CO}$ dan $\mathrm{HC}$ paling rendah terjadi pada $1500 \mathrm{rpm}$ dengan kadar gas $\mathrm{CO}$ sebesar $2,54 \%$ dengan kadar HC sebesar 7273 ppm, dan kadar emisi gas $\mathrm{CO}$ paling tinggi terjadi pada $4000 \mathrm{rpm}$ yaitu sebesar $4,56 \%$ dan kadar gas HC mengalami kenaikan tertinggi pada putaran mesin $4000 \mathrm{rpm}$ sebesar $9.999 \mathrm{ppm}$.

2. Pengaruh penggunaan catalytic converter dengan bahan tembaga 0,6 $\mathrm{mm}$ dengan model sirip mengalami penurunan kadar emisi gas $\mathrm{CO}$ paling efektif pada putaran mesin $1500 \mathrm{rpm}$ sebesar 2,357\% dari 4,89\% menjadi 2,54\% dan nilai kadar emisi gas $\mathrm{HC}$ turun pada rpm 1500 sebesar 2726 ppm dari 9.999 ppm menjadi 7273 ppm.

\section{UCAPAN TERIMAKASIH}

Kami ucapkan terima kasih banyak kepada ketua program studi Teknik mesin Diploma Tiga dan ketua Lab Teknik Universitas Muhammadiyah Pekajangan Pekalongan atas fasilitas yang diberikan Fasilitas sehingga penelitian ini dapat berjalan dengan baik

\section{REFERENSI}

[1] O. Sriyanto, "Pengaruh tipe busi terhadap emisi gas buang sepeda motor," Automot. Exp., vol. 1, no. 03, pp. 64-69, 2018.
[2] P. S. Pasaribu, "Pengaruh Celah Katup Dan Campuran Bahan Bakar Pertamax Turbo Dengan Premium Terhadap Emisi Gas Buang Pada Mobil 1500 Cc"," Ojs-unita.com, vol. 1, no. 2, p. 283, 2019, doi: 10.1017/CBO9781107415324.004.

[3] A. N. Syaief, M. Adriana, and A. Hidayat, "Uji Emisi Gas Buang Dengan Perbandingan Jenis Busi Pada Sepeda Motor 108 Cc," Elem. J. Tek. Mesin, vol. 6, no. 1, p. 01, 2019, doi: 10.34128/je.v6i1.82.

[4] S. Aswito, "Pengaruh Catalytic Converter Dengan Model Jaring Terhadap Emisi Gas Buang Pada Kendaraan Bermotor," J. Tek. Mesin Univ. Islam Malang, pp. 2834, 2017.

[5] W. WibisonoIskandar, "Tembaga Berlapis Mangan Terhadapterhadap Reduksi Emisi Gas Buang Suzuki Satria Fu 150," JTM Univ. negeri Surabaya, vol. 3, no. 2, pp. 207216, 2010.

[6] M. S. CholilullohWarju, "Engaruh Metallic Catalytic Converter Tembaga Berlapis Krom Dan Air Induction System (Ais) Terhadap Reduksi Emisi Gas Buang Yamaha New Jupiter Mx," JTM , Jur. Tek. Mesin Fak. Tek. Univ. Negeri Surabaya, vol. 03, no. 2, pp. 104113, 2014.

[7] W. Rido Manuggal, "Pengaruh Penggunaan Metallic Catalytic Converter Berbahan Tembaga Dan Aplikasi Teknologi Sass Terhadap Performa Sepeda Motor Honda New Mega Pro," JTM , Univ. Negeri Surabaya, vol. 1, no. 2, pp. 110-115, 2008.

[8] A. E. N. Sulton Hari Satrio Utomo1, Nely Ana Mufarida2, "Pengaruh Catalytic Converter Tembaga $\quad(\mathrm{Cu}) \quad$ Terhadap Konsentrasi Gas Karbon Monoksida (Co) Dan Hidro Karbon (Hc) Pada Gas Buang Sepeda Motor 4 Langkah 125 Cc," J. Tek. Mesin Univ. Muhammadiyah 
Jember, pp. 1-9, 2017.

[9] R. Ubaidillah, "Analisa Perbandingan Emisi Gas Buang Dengan Menggunakan Catalytic Converter Berbahan Baja , Kuningan Dan Tembaga," 2018.

[10] S. Rachmadhi, "Pengaruh Jarak Kerenggan Celah Elektroda Busi Terhadap Emisi Gas Buang Pada
Sepeda Motor 4 Tak," J. Tek. Mesin Unp, vol. 53, no. 9, pp. 1689-1699, 2017 , doi: 10.1017/CBO9781107415324.004.

[11] S. Pasaribu, "Pengaruh Variasi Celah Busi Dan Jenis Busi Terhadap Emisi Gas Buang Pada Kendaraan Roda Dua 110Cc," Integritas, vol. 3, no. 1, 2017. 